Original Article

\title{
Oral Hygiene Awareness on Patients Attending Dental OPD in A.B. Shetty Memorial Institute of Dental Sciences
}

\author{
Anjhana Asok ${ }^{1}$, Rahul Bhandary ${ }^{2}$, M amatha Shetty $^{3}$, SmithaShetty ${ }^{4}$, Amitha Ramesh $^{5}$ \\ ${ }^{1}$ Postgraduate, ${ }^{2,5}$ Professor, ${ }^{3}$ Reader, ${ }^{4}$ Senior Lecturer, Department of Periodontics, A.B. Shetty M emorial Institute of Dental \\ Sciences, Nitte Deemed to be University, Derlakatte, Mangalore.
}

*Corresponding Author : Anjhana Asok, Department of Periodontics, A.B. Shetty M emorial Institute of Dental Sciences, Nitte (Deemed to beUniversity), Derlakatte, M angalore. Mobile : $+919686924421 . \quad$ E-mail : anjhanaasok91@gmail.com

$\begin{array}{ll}\text { Received } & : 16.08 .2017 \\ \text { Review Completed } & : 12.12 .2017 \\ \text { Accepted } & : 13.12 .2017\end{array}$

Keywords : Oral hygiene awareness, general health, oral health, motivate

\begin{tabular}{|c|}
\hline Access this article online \\
\hline Quick Response Code \\
\hline
\end{tabular}

\begin{abstract}
Background-Oral hygiene is highly personalised concept and major public health concern that relies on an individual's culture and socio-economic status. Hence, it is imperative that health services should be made available to all rural/semi urban areas as well.Thus it is important to create awareness through various public health programs regarding oral hygiene and its effects on general health in order to change the total perspective of the patients towards dental problems to lead a healthy qualitylife.
\end{abstract}

Objective-Thus the aim of this study is to assess the oral hygiene awareness and their knowledge on different oral hygiene practices.

Materials and M ethods- A total of 369 patients participated in the study.. The patients were interviewed on questionnaire basis. A self-reported questionnaire consisting of 26 multiple choice questions written in English were given to the patients.

Statistical analysis-Descriptive statistics such as frequency and percentage was used to assess the oral health awareness and oral hygiene practice among the subjects who are attending $A . B$ Shetty M emorial Institute Of Dental Sciences, Derlakatte, M angalore.

Results- The result of this study showed an acute lack of oral hygiene awareness and limited knowledge of oral hygiene practices. Most of the patients were not aware of the relationship between systemic and general health.

Conclusion- Hence there is an urgent need to educate and motivate the patients for better oral hygiene awareness and practises and conduct various health programs for the same.

\section{Introduction}

Oral hygiene is highly personalised concept and major public health concern that relies on an individual's culture and socio-economic status. It can be defined as a standard of health of the oral and related tissues, which enables an individual to eat, speak and socialize without active disease, discomfort or embarrassment and which contributes to general wellbeing. ${ }^{1}$ the possible factors that affect oral health are poor oral hygiene, developmental problems, trauma and genetic predisposition. Oral health attitude and awareness are significant for oral health behaviour. Patients cooperate with oral health care regimens when they are informed and positively motivated. The factors which decide the oral hygiene in a population depends upon the outlook of the patients towards their dentition. Oral health is equally important as general health. Oral health is an integral part of general health; therefore, its disregarding will give rise the negative health and social consequences. It affects physical and psychological and social wellbeing of a person.

Chronic diseases such as diabetes, obesity and caries, which share common risk factors are on an increase in developing countries leading to poor quality of dental as well as general health. ${ }^{2,3}$ People tend to ignore the oral health related problems that can have a serious impact towards their overall health and eventually cause toothache and leave patients with few teeth. Although many studies have been carried out from time to time to assess the knowledge and behaviour of people about oral 
health, there is still a dearth of education regarding the same especially for rural people, who make up for more than $70 \%$ of the population in India. ${ }^{4}$ Dental caries and periodontal diseases have historically been considered the most important global oral health burdens. At present, the distribution and severity of oral diseases vary in different parts of world and within the same country or region.

India is a vast country with diverse cultural practices, dietary habits, and geographical variations. About $60-70 \%$ of the population resides in rural areas. Rural mass is generally not able to reap the benefits compared to the urban residents. Hence, it is imperative that health services should be made available to all rural/semi urban areas as well. Such people have been known not to seek dental care for a variety of reasons such as social reasons, physical reasons, psychological reasons etc., Furthermore, even the people living in cities, in spite of having easy reach to dental care, fall prey to dental diseases due to their negligence in dietary habits and unhealthy lifestyle. ${ }^{5}$ The attitude of people toward their own teeth and the attitude of dentists who provide dental care, play an important role in determining the oral health condition of the population.

Thus it is important to create awareness through various public health programs regarding oral hygiene and its effects on general health in order to change the total perspective of the patients towards dental problems to lead a healthy quality life. Thus the aim of this study is to assess the oral hygiene awareness and their knowledge on different oral hygiene practices.

\section{Aims and Objective}

1. To assess the oral hygiene awareness among patients attending the out-patient department in A. B. Shetty Memorial Institute Of Dental Sciences, M angalore.

2. To assess their knowledge on different oral hygiene practices.

\section{Materials and Methods}

\section{Screening Examination}

A total of 369 patients attending the out-patient department of A.B. Shetty Memorial Institute Of Dental
Sciences, Deralakatte, $M$ angalore during the month of $M$ ay 2016 to July 2016 were included in the study. The patients were interviewed on questionnaire basis. A self-reported questionnaire consisting of 26 multiple choice questions written in English were given to the patients.

\section{Inclusion Criteria}

1. Patients attending dental out-patient department of A.B.Shetty Memorial Institute Of Dental Sciences, Deralakatte, M angalore.

2. Patients who are willing to give verbal consent were included in the study.

\section{Exclusion criteria}

1. Patients who are not willing to participate in the study.

2. Patients with mental illness, maxillofacial trauma and who are unable to respond to the questions in the study.

\section{Statistical Analysis}

Descriptive statistics such as frequency and percentage was used to assess the oral health awareness and oral hygiene practice among the subjects who are attending A.B Shetty Memorial Institute of Dental Sciences, Derlakatte, Mangalore.

\section{Results}

In the present study questionnaire was distributed to 369 patients who were selected randomly. Of the 369 participants $70 \%$ were males and $30 \%$ were females. The results are represented below graphically. (Fig 1-13) 
Figure 1 : Percentage of males and females

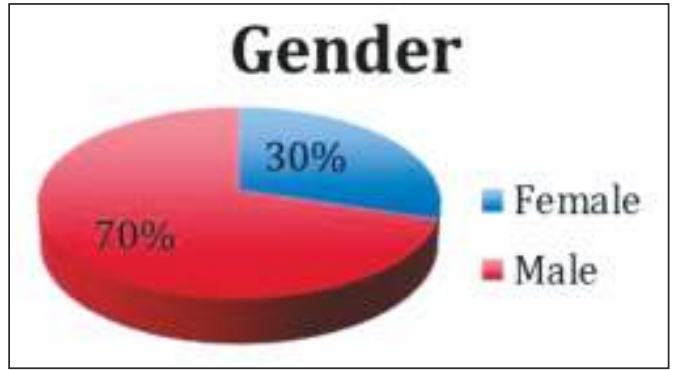

The various responses to the different type of questions asked have been shown in the graphs below.

Figure 2 : Different types of cleaning methods other than tooth brushing

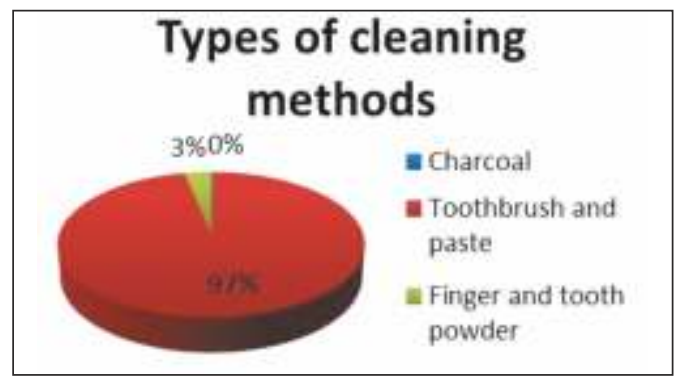

Figure 3 : Brushing frequency

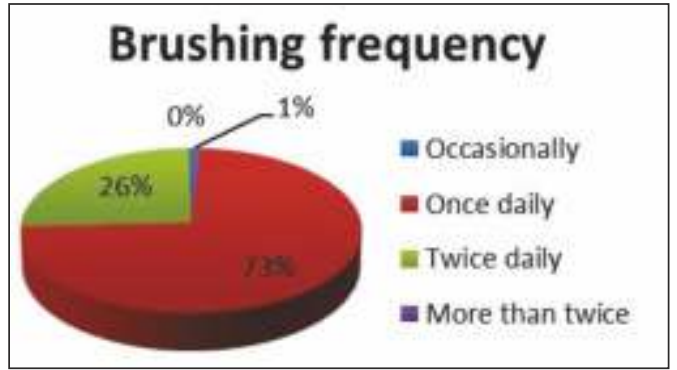

Figure 4 : Types of tooth brush being used

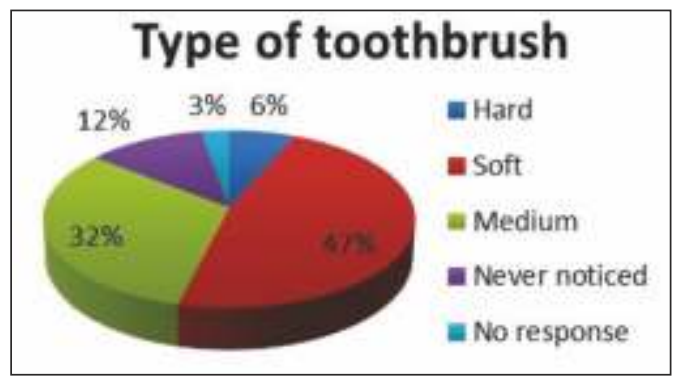

Figure 5 : Different types of brushing technique

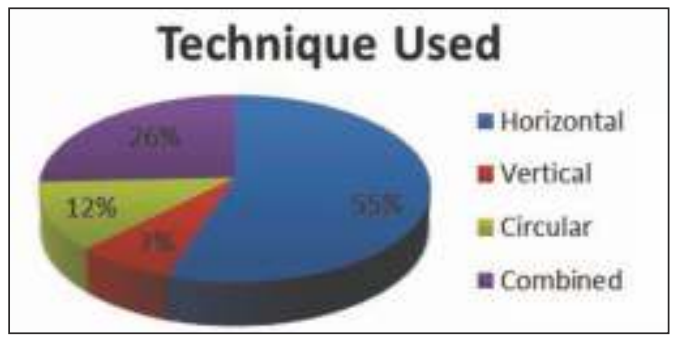

Figure 6 : Percentage of patients changing toothbrush

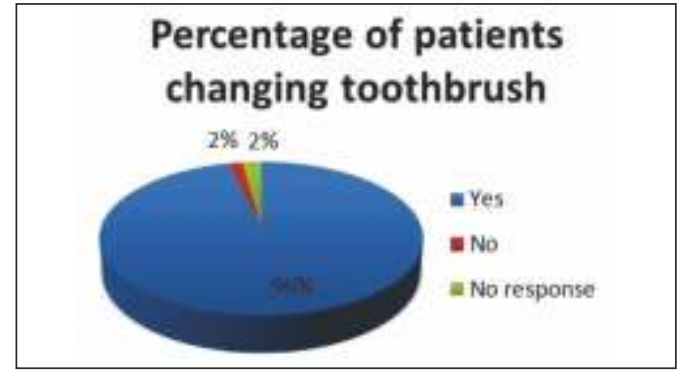

Figure 7 : Frequency of changing toothbrush

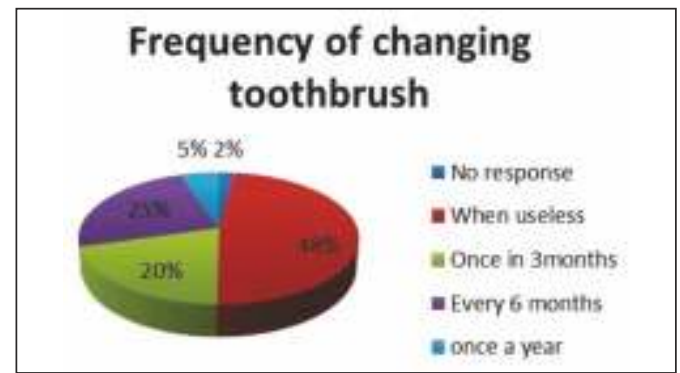

Figure 8 : Duration while brushing

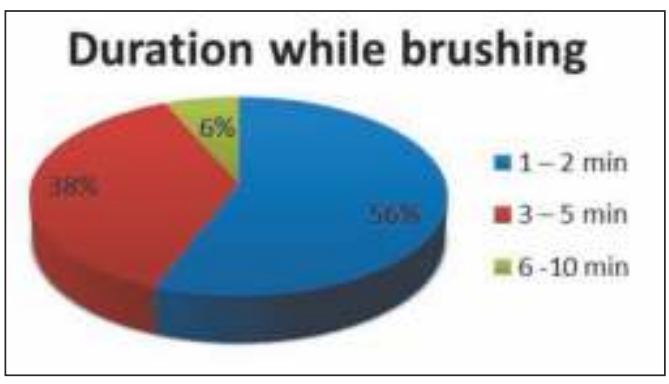

Figure 9 : Percentage of patients having knowledge about inter-dental aids

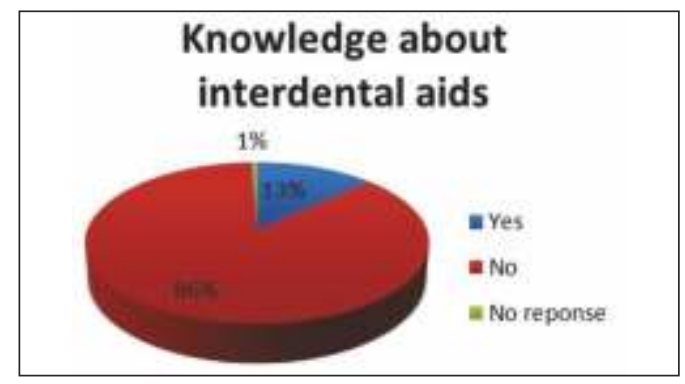

Figure 10 : Percentage of patients using different types of interdental aids

\section{Type of interdental aids}

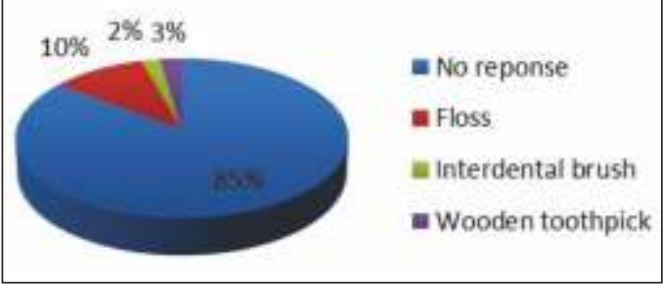


$36.6 \%$ of the patients clean their tongue, $98.4 \%$ rinse their mouth, $8.7 \%$ use mouthwash, $25.2 \%$ of the patients noticed bleeding while brushing, $21.4 \%$ noticed halitosis and $95.4 \%$ of the patients visited dentist.

Figure 11 : Positive response obtained for tongue cleaning, using mouthwash, bad breath, bleeding and visiting dentist

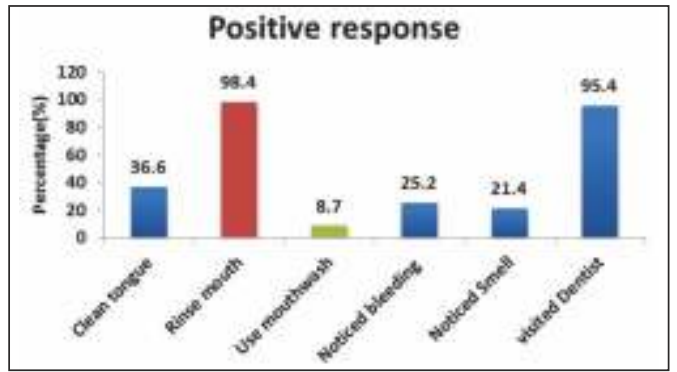

Figure 12 : Frequency of visiting dentist

\section{Frequency of visiting dentist}

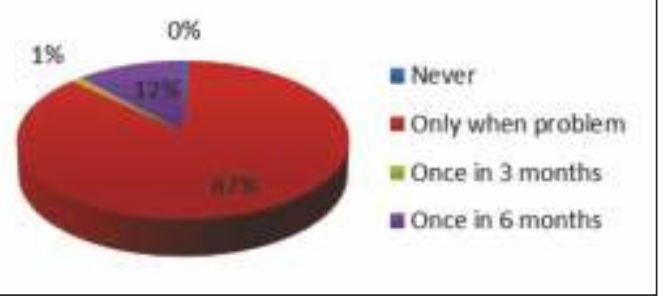

Among 369 participants who participated in the survey, 262 patients wanted cleaning and 107 patients did not want cleaning. It was also noted that only 53 patients had an idea about the relationship of oral health and general health while 316 patients think that there is no link between oral health and general health.

Figure 13 : Patients who wanted cleaning and subjects who think oral health affects general

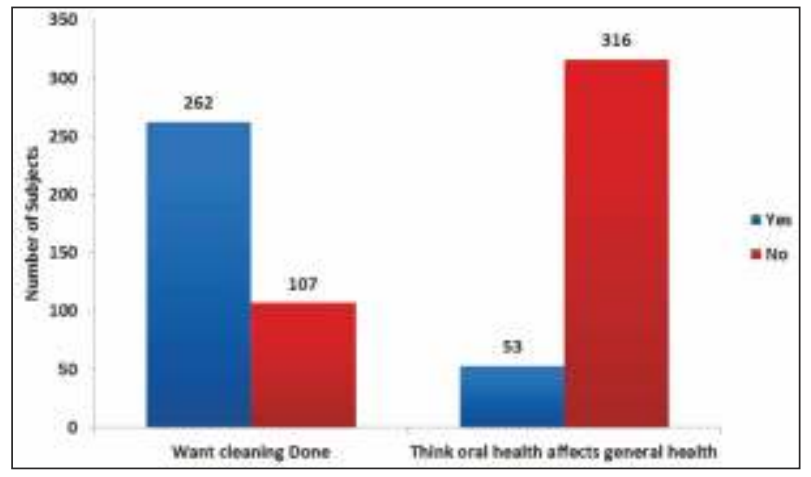

\section{Discussion}

Oral health is equally important as general health. As more and more percentage of patients has fear regarding their dental health and treatment needs, such actions lead to treatment delay and avoidance behaviour towards oral care and health in general. People should be made aware of all these facts in order to lead a healthy and longer life.

Unfortunately, oral health standards in India still pose a major problem due lack of awareness. ${ }^{5}$. Most diseases show their first appearance through oral signs and symptoms and they remain undiagnosed or untreated because of this missing awareness. According to a survey conducted in 2011, only 58\% of the patients used toothbrush and toothpaste. ${ }^{6}$ According to the consumer usage and attitudes study done in 2010, among the most shocking of revelations is that nearly half of the Indian population does not use a tooth brush and only 51\% brushed their teeth using a tooth brush and toothpaste. Preventive oral health knowledge, behaviour, and its practice are the important ways of keeping our teeth healthy and it also improves our quality of life. Hence, in this study attempts were made to evaluate preventive oral health knowledge, practice, and behaviour of the subjects who attended the dental OPD in AB Shetty Dental College.

The percentage of patients brushing their teeth twice daily in this was only $26 \%$ which is less when compared with $62 \%$ of the Kuwaiti adults in a study by Al-Shammari et al ${ }^{8}$ and $50 \%$ of the middle aged and $75 \%$ of the elderly Chinese adults in urban areas in a study by Zhu et al. ${ }^{9}$

In this study, 55\% of the patients used horizontal method of brushing which will jeopardize the tooth structure. This is less compared to the study done in a population in Jodhpur by Jain et al ${ }^{6}$ where $75 \%$ of the patients used the same method. A study done by Zhu et al ${ }^{9}$ showed $60 \%$ of the patients using this method which was similar to the present study.

It was noteworthy that $47 \%$ of the patients used soft brush which was more compared to the study done by Jain et al ${ }^{6}$ and Zhu et al ${ }^{9}$ where $10 \%$ and $27 \%$ of the patients used soft brush.

$48 \%$ of the patients changed toothbrush when useless and only $20 \%$ changed once in 3 months. This is similar to the 
study done by Jain et $\mathrm{al}^{6}$ where $30 \%$ of the participants changed once in 3 months and $60 \%$ changed when useless.

There is generally a failure in the use of dental floss as a preventive tool. $86 \%$ of the participants did not know about interdental aids. In a study conducted in Saudi Arabia by Jamjoom ${ }^{10}$ in 2001, where no patients used dental floss for interdental cleaning, which is similar to our results. In the present study about $15 \%$ of the total patients used any of the interdental aids, out of which only $10 \%$ subjects used dental floss, $3 \%$ patients used toothpick while only $2 \%$ patients used interdental brush. In contrast, Hamilton and Couby found that a high percentage (44\%) of the sample they studied in north eastern Ontario used dental floss. ${ }^{11}$ The reason for this may be the significant resource allocation to health education programs that are carried out in Canada. This emphasizes the immediate need for educating and motivating the public to use this efficient method for oral health care.

Only $36.6 \%$ of the patients cleaned their tongue in the present study which is in contrast to the study done by Kapoor et a ${ }^{12}$ in 2014 where $67.2 \%$ of the patients cleaned their tongue, while in the study by Jain et al ${ }^{6}$ only $20 \%$ of the studied population cleaned their tongue which is similar to the present study. This basic and simple method of maintaining oral hygiene is not very much popular among most of the population which shows lack of oral health awareness.

Only $8.7 \%$ of the patients used mouthwash and $25.2 \%$ noticed bleeding while brushing in the present study. (See figure11). In a study by Jain et al $40 \%$ of the total population noticed bleeding gums. Bad breath was experienced by $21.4 \%$ of the patients which is in contrast to the study by Jain et al ${ }^{6}$ and Kapoor et al ${ }^{12}$ where $80 \%$ and $47.2 \%$ of the population respectively complained of malodour. An epidemiologic survey of the general population of Japan, where $24 \%$ of the individuals examined complained about bad breath shows similar results to the present study. ${ }^{13}$ The study done by Kumar et al also showed similar results where $21 \%$ of the patients complained about bad breath. ${ }^{14}$
It was interesting to note that $95.4 \%$ of the total patients visited dentist which was similar to the study done by Kapoor et $\mathrm{al}^{12}$ where $75 \%$ of the patients visited dentist and $54 \%$ of the patients visited dentist only when they have pain in a study by Jain et al ${ }^{6}$. Only $12 \%$ of the patients visited dentist every 6 months and $87 \%$ of the patients visited only when they had a problem. It is in agreement to the study done by Kapoor et $\mathrm{al}^{12}$ where around $75 \%$ of the patients visited the dentist only in problem and only $10 \%$ of the population visited the dentist on regular basis after every 6 months. About $60 \%$ of the patients in the never visited a dentist and about $40 \%$ of the remaining only visited in case of a problem in a study by Gill et al ${ }^{5}$ which was contrast to the present study. In a study conducted by Jiang et $\mathrm{al}^{15}$ only $26 \%$ of the students visited a dentist during the previous 12 months.

M ajority of the people are unaware about the relationship between oral hygiene and systemic diseases or disorders. In the current study only 53 patients (14\%) of the total 369 patients knew about the relationship between oral health and systemic health which is in contrast to the study done by Kapoor et $\mathrm{al}^{12}$ where $43.2 \%$ had an idea about the relationship between oral and systemic health and study done by Karim et $a 1^{16}$ where $43.36 \%$ of the patients were aware of the relationship between oral and general health.

\section{Conclusion}

The present study shows that there is lack in appropriate oral health awareness even among literates. Moreover, majority of the patients were not aware of the fact that oral health has an effect on systemic health. Hence, there is a need to educate and spread knowledge of proper dental care and prevention of dental diseases through the dentists, outreach programs and relevant public health awareness measures to make a healthy individual and a healthy society.

The task of spreading this awareness extends beyond our clinic to general population and it will have to be achieved in a similar way by various outreach programs and relevant public health awareness measures through various mediums, such as Print/Press Media, Audio/Radio/ 
Television, Internet, and Organizing Social Activities. All of these and more innovative methods of reaching the public

\section{References}

1. Singh A, Gambhir RS, Singh S, Kapoor V, Singh J. Oral health: How much do you know? - A study on knowledge, attitude and practices of patients visiting a North Indian dental school. EurJ Dent 2014;8:63-7.

2. Ashley FP. Role of dental health education in preventive dentistry. In prevention of dental disease. 3rd ed. In: M urray JJ, editor. Oxford: Oxford University Press; 1996. p. 406-14.

3. Petersen PE, Bourgeois D, Ogawa H, Estupinan-Day S, Ndiaye C. The global burden of oral diseases and risks to oral health. Bulletin of the World Health Organization. 2005; 83: 661-9.

4. Patil AV, Somasundaram KV, Goyal RC. Current health scenario inrural India. Aust J Rural Health 2002;10:129-35.

5. Gill M, Pal K, Gambhir RS. Oral hygiene practices, attitude, and access barriers to oral health among patients visiting a rural dental college in North India.J Dent Res Rev 2014;1:114-7.

6. Jain N, Mitra D, Ashok KP, Dundappa J, Soni S, Ahmed S. Oral hygieneawareness and practice among patients attending OPD at Vyas Dental College and Hospital, Jodhpur.J Indian SocPeriodontol 2012;16:524-8.

7. Cosmetic dentistry guide: The consumer usage and attitudes survey: Available from: http://www.cosmeticdentistryguide. co.uk/news/ survey-indicates-poor-standards-oforal-health-inindia-9321 [Last accessed on 2010 Apr 16].

8. Al-Shammari KF, Al-Ansari JM, Al-Khabbaz AK, Dashti A, Honkala EJ. Selfreported oral hygiene habits and oral health problems of Kuwaiti adults. Med PrincPract 2007;16:15-21. will not only ensure a healthy individual but a healthy societyas well.

9. Zhu L, Petersen PE, Wang HY, Bian JY, Zhang BX. Oral health knowledge, attitudes and behaviour of adults in China. Int Dent 2005;55:231-41.

10. Jamjoom HM. Preventive Oral Health Knowledge and Practice in Jeddah, Saudi Arabia.J KAU: M ed Sci 2001;9:17-25.

11. Hamilton ME, Coulby WM. Oral health knowledge and habits of senior elementary school students. J Publ Health Dent 1991;51:212-8.

12. Kapoor D, Gill S, Singh A, Kaur I, Kapoor P. Oral hygiene awareness and practice amongst patients visiting the Department of Periodontology at a Dental College and Hospital in North India. Indian J Dent 2014;5:64-8.

13. M iyazaki H, Sakao S, Katoh Y, Takehara T. Oral malodor in the general population of Japan. Bad Breath: Research Perspectives. Israel: Ramot Publishing: Tel AvivUniversity; 1995. p. 119-36.

14. Kumar S. Oral Hygiene Awareness among Two Non Professional College Students in Chennai, India- A Pilot Study. Adv Life SciTechnol 2012;5:31-6.

15. Jiang H, Petersen PE, Peng B, Tai B, Bian Z. Self-assessed dental health, oral health practices, and general health behaviors in Chinese urban adolescents. ActaOdontolScand 2005;63:343-52.

16. Karim A. S. Oral health Knowledge, attitudes and behaviour among a sample of Kurdish people in Sulaimani governorate. IOSR-JDM S. 2015; 14 (11): $72-77$ 